\title{
Diversity, Biogeography and Community Ecology of Ants: Introduction to the Special Issue
}

\author{
Alan N. Andersen (D) \\ Research Institute for the Environment and Livelihoods, Charles Darwin University, Darwin, NT 0909, Australia; \\ alan.andersen@cdu.edu.au; Tel.: +61-468-384-038
}

check for

updates

Citation: Andersen, A.N. Diversity, Biogeography and Community

Ecology of Ants: Introduction to the Special Issue. Diversity 2021, 13, 625. https://doi.org/10.3390/d13120625

Received: 23 November 2021 Accepted: 26 November 2021 Published: 28 November 2021

Publisher's Note: MDPI stays neutral with regard to jurisdictional claims in published maps and institutional affiliations.

Copyright: (C) 2021 by the author. Licensee MDPI, Basel, Switzerland. This article is an open access article distributed under the terms and conditions of the Creative Commons Attribution (CC BY) license (https:/ / creativecommons.org/licenses/by/ $4.0 /)$.
Ants are a ubiquitous, highly diverse and ecologically dominant faunal group. They represent up to half of total insect biomass globally, and their biomass exceeds that of all vertebrates combined in most terrestrial biomes. Ants are deeply connected within terrestrial ecosystems. They play key roles as soil engineers, predators and re-cyclers of nutrients. They have particularly important interactions with plants as defenders against herbivores, as seed dispersers and as seed predators; as such they have had a significant influence on plant evolution and diversification. The deep connections of ants with ecosystems means that ant-species composition can provide important insights into ecosystem health. Combined with their ubiquity and ease of sampling, this has seen ants widely used as bio-indicators in land management.

One downside to the ecological dominance of ants is that they feature on the list of the world's worst invasive species. Species such as the red imported fire ant (Solenopsis invicta), yellow crazy ant (Anoplolepis gracilipes), African big-headed ant (Pheidole megacephala) and Argentine ant (Linepithema humile) have been inadvertently transported throughout the world and have invaded both agricultural and native ecosystems, with devastating impacts.

The importance of ants can be seen in more than just their ecological impacts; ants have been a transformative taxon through their contributions to a scientific understanding of biodiversity as model organisms for studies of diversity, biogeography and community ecology. Studies of ants have been foundational to the development of ecological theory relating to diversity and its distribution, such as the taxon cycle and island biogeography. They have made seminal contributions to an understanding of niche dynamics, species co-existence, community assembly and disturbance dynamics.

Despite their ecological dominance and their role as model organisms for ecological research, ants remain remarkably understudied. A large proportion of species remain undescribed, the biogeographic histories of most taxa remain poorly known, and we have a limited understanding of the spatial patterns of diversity and composition, along with the processes driving these patterns. The ten papers in this Special Issue address all these themes.

Three papers [1-3] make a significant contribution to our understanding of undocumented ant diversity. Two of these [1,2] are from Australia, illustrating the extent to which the remarkably megadiverse ant fauna of this continent remains undocumented. One relates to a large and conspicuous 'species' of the arid-adapted formicine genus Melophorus that is endemic to Australia [1]. It provides an integrated genetic, morphological and distributional analysis of diversity within $M$. 'rufoniger' in a 400,000 km² region (the 'Top End' of the Northern Territory) of Australia's monsoonal (seasonal) tropics. Thirty species from this taxon were recognized from 120 sequenced specimens, with all but two apparently endemic to the region. The findings indicate that up to 100 or more species from this taxon occur in monsoonal Australia, and are all undescribed. The study provides further evidence that the total Melophorus fauna comprises well over an astonishing 1000 species, which is an order of magnitude higher than any other arid-adapted ant genus found elsewhere in the world. 
The second Australian paper documents the unrecognized diversity of the ecologically dominant dolichoderine genus Anonychomyrma in rainforests of the Wet Tropics bioregion of North Queensland. The study drew on extensive recent collections along elevational and vertical (arboreal) gradients in five upland subregions spanning the full latitudinal range of the bioregion. Integrated morphological, genetic (CO1) and distributional analyses led to the recognition of 22 species, all but two of which appear to be undescribed.

The third paper describing undocumented diversity [3] does so in an urban context. Recently, there has been a considerable level of interest in the biodiversity values of urban areas, both in terms of their conservation significance as refuges for biodiversity, and their potential as gateways for invasive species. Ants are an ideal taxon for examining this. The study in [3] reports on a comprehensive ant survey of Macao, a highly urbanized $\left(20,000\right.$ people $\left./ \mathrm{km}^{2}\right)$ territory in subtropical China. The survey detected 55 new species records for Macao, bringing its total known ant fauna to 155 species, 18 of which are exotic. Several of the newly recorded species appear to be entirely new to science; these include species of Strumigenys, Syllophopsis and Tetramorium that were collected only from subterranean traps. The study also includes a compilation of ant diversity in 112 other urban areas throughout the world. The overall findings are that urban ant faunas are often highly diverse and can have high conservation value, including harboring previously uncollected species. However, urban areas are likely to facilitate the establishment and subsequent spread of exotic species.

The documentation of diversity within the Anonychomyrma fauna within Australia's wet tropics [2] was conducted in the context of understanding the fauna's biogeographic origins. Despite its high diversity in the humid tropics of both Australia and New Guinea, the genus is believed to have a cool-temperate Gondwanan origin. This leads to the prediction that the tropical fauna is concentrated at higher elevation. Moreover, Australia's tropical rainforest has undergone extensive contractions and expansions during climatic fluctuations over recent geological history, such that only small areas have supported rainforests throughout this period. Diversity and endemism within Anonychomyrma can therefore be expected to be concentrated in these refuge areas. As predicted, diversity and endemism were concentrated at a higher elevation ( $>900 \mathrm{~m}$ above sea level), and especially in refuge areas where rainforest had been maintained throughout the late quaternary.

The biogeographic theme continues in the Special Issue with an analysis of the Iberian (Spain, Portugal, Gibraltar and Andorra) ant fauna [4], one of the richest and most distinctive in the Mediterranean region with 299 recorded species, including 72 endemics. Rates of endemism (proportions of total species) vary markedly among genera, being particularly high in Temnothorax, Goniomma and Cataglyphis, and low in Formica, Lasius and Tetramorium. The high diversity and endemism can be attributed to the peninsula's complex topography and high environmental heterogeneity, which is reflected by the fauna showing pronounced biogeographic regionalization. The biogeographical origins of the fauna are primarily Palearctic, but also include central Asia (e.g., Myrmica, Proformica) and even the Nearctic (Stenamma). Dispersal from central Asia has likely occurred through both northern Africa and southern Europe. This analysis makes an important contribution to an understanding of the evolutionary history and biogeography of the Iberian Peninsula more generally.

The proximate mechanisms underlying species distributions are poorly understood, and this is the focus of a study of ant species occurring along an elevational gradient in Great Smoky Mountains National Park in south-eastern USA [5]. Thermal tolerance appeared to be the most important constraint on the distribution and density of ant species in colder (higher elevation) environments, whereas competition was identified as a key factor in warmer (lowland) environments. These findings indicate that species' responses to global warming are likely to be highly dependent on geographic context.

Ants can act as model organisms for understanding evolution and biogeography in a different way-as hosts of microorganisms [6]. Wolbachia bacteria are one of the most common and widely distributed microorganisms infecting insects, but the origins and 
dispersion patterns within different insect groups are poorly understood. The strains of Wolbachia are classified into 17 supergroups, and the analysis in [6] indicates that supergroup $\mathrm{F}$ is the ancestral character state for Wolbachia infection in ants. The infection of ants likely originated in Asia, before undergoing complex patterns of dispersal throughout the world, including through one route to South America and back to Asia before dispersing to Oceania and Madagascar.

Two papers in the Special Issue address the structure and dynamics of ant communities. The first [7] uses a wide range of sampling methods, incorporating diverse food resources along with sampling in different vertical strata, to examine niche partitioning in rainforest ant communities of French Guiana and Borneo. Many cryptobiotic species were recorded primarily or exclusively at subterranean baits, which supports findings from several recent studies (including [3]) that a diverse fauna of highly specialized hypogaeic species is characteristic of the tropics. Subterranean ants generally had more specialized food preferences than above-ground ants, and this was true for individual species foraging in both strata.

The second paper on community ecology [8] examines the extent to which a numerically dominant ant (Formica subsericea) affects the diversity and performance of co-occurring species. As in [5], the study was conducted in the Great Smoky Mountains National Park, where F. subsericea is particularly common. There was no relationship between the abundance of F. subsericea and the total abundance of non-dominant species across the ten sites studied, and the relationship with total species richness was weak. There was therefore little or no evidence of competitive exclusion. A comparison of colonies of two co-occurring species (Aphaenogaster rudis and Nylanderia faisonensis) located close to $(\leq 1 \mathrm{~m})$ and distant $(5-10 \mathrm{~m})$ from $F$. subsericea nests revealed no differences in either colony size or brood production. There was, therefore, no evidence that competition from $F$. subsericea affected colony performance for either species. Markedly fewer workers of $A$. rudis occurred during the day at baits close to, compared with distant from, F. subsericea nests, but this was not the case for either Nylanderia faisonensis or Myrmica punctiventris. Formica subsericea thus had only a limited effect on resource acquisition by other species, even close to their nests. However, the number of other ants recorded at baits during the night, when F. subsericea was largely inactive, was found to be twice that recorded during the day, suggesting an avoidance of competition through temporal niche partitioning.

The final two papers of the Special Issue deal with ant taxa that are particularly influential in the ecosystems in which they occur. The first [9] is a comprehensive review of Eciton army ants. These are iconic top predators in Neotropical forests and are remarkable for the diversity of faunal taxa that are associated with them, often obligately so. Their most famous associates are the 'antbirds' that feed primarily on arthropods flushed during Eciton raids. Such specialization has evolved independently within multiple avian families. An astonishing variety of invertebrates have intimate associations with Eciton colonies, many with highly specialized morphological, behavioural and/or chemical traits that facilitate their integration into colony life. Eciton colonies require large forested areas, which, combined with their ecological importance, makes them ideal 'umbrella' taxa for the identification of priority areas for conservation and for assessments of disturbance impacts in Neotropical forests.

The final paper [10] describes an unwelcome impact- that of the red imported fire ant Solenopsis invicta, one of the world's most destructive invasive species. The gopher tortoise (Gopherus polyphemus) of the southeastern United States is an ecosystem engineer, whose burrows provide habitat for at least 60 vertebrate and 302 invertebrate species, many of which are of conservational interest. Gopher burrows are often colonized by fire ants, effectively concentrating their impacts on native fauna. The impact on native invertebrates was investigated at ten sites in southern Mississippi by sampling burrows before and after bait treatments to reduce fire ant populations. Baiting reduced fire ant abundance in burrows by $>98 \%$, and this had a positive effect on the abundance and diversity of other invertebrates as measured by vacuum sampling. It was concluded that targeted fire-ant 
management around the burrows of gopher tortoises is likely to have a disproportionate benefit for native biodiversity.

The papers in this Special Issue collectively address many of the most pressing questions relating to ant diversity. What is the level of ant diversity? What is the origin of this diversity, and how is it distributed at different spatial scales? What are the roles of niche partitioning and competition as regulators of local diversity? How do ants affect the ecosystems within which they occur? The papers in this Special Issue give important answers to these questions. These answers are not just relevant to ants, but provide valuable insights for biodiversity more generally.

Conflicts of Interest: The author declares no conflict of interest.

\section{References}

1. Andersen, A.N.; Hoffmann, B.D.; Oberprieler, S.K. Megadiversity in the ant genus Melophorus: The M. rufoniger Heterick, Castalanelli and Shattuck species group in the Top End of Australia's Northern Territory. Diversity 2020, 12, 386. [CrossRef]

2. Leahy, L.; Scheffers, B.R.; Williams, S.E.; Andersen, A.N. Diversity and distribution of the dominant ant genus Anonychomyrma (Hymenoptera: Formicidae) in the Australian Wet Tropics. Diversity 2020, 12, 474. [CrossRef]

3. Brassard, F.; Leong, C.-M.; Chan, H.-H.; Guénard, B. High diversity in urban areas: How comprehensive sampling reveals high ant species richness within one of the most urbanized regions of the world. Diversity 2021, 13, 358. [CrossRef]

4. Tinaut, A.; Ruano, F. Biogeography of Iberian ants (Hymenoptera: Formicidae). Diversity 2021, 13, 88. [CrossRef]

5. Chick, L.D.; Lessard, J.-P.; Dunn, R.R.; Sanders, N.J. The coupled influence of thermal physiology and biotic interactions on the distribution and density of ant species along an elevational gradient. Diversity 2020, 12, 456. [CrossRef]

6. Ramalho, M.O.; Moreau, C.S. The evolution and biogeography of Wolbachia in ants (Hymenoptera: Formicidae). Diversity 2020, 12, 426. [CrossRef]

7. Houadria, M.; Menzel, F. Digging deeper into the ecology of subterranean ants: Diversity and niche partitioning across two continents. Diversity 2021, 13, 53. [CrossRef]

8. Lessard, J.-P.; Stuble, K.L.; Sanders, N.J. Do dominant ants affect secondary productivity, behavior and diversity in a guild of woodland ants? Diversity 2020, 12, 460. [CrossRef]

9. Pérez-Espona, S. Eciton Army ants-Umbrella species for conservation in neotropical forests. Diversity 2021, 13, 136. [CrossRef]

10. Epperson, D.M.; Allen, C.R.; Hogan, K.F.E. Red imported fire ants reduce invertebrate abundance, richness, and diversity in gopher tortoise burrows. Diversity 2021, 13, 7. [CrossRef] 